Pablo Villoslada, MD

Alex Rovira, MD

Xavier Montalban, MD

Rafael Arroyo, MD

Friedemann Paul, MD

Virginia Meca-Lallana,

MD

Cristina Ramo, MD

Oscar Fernandez, MD

Albert Saiz, MD

Antonio Garcia-Merino, MD

Lluís Ramió-Torrentà, MD

Bonaventura Casanova, MD

Celia Oreja-Guevara, MD

Delicias Muñoz, MD

Jose Enrique Martinez-

Rodriguez, MD

Eckart Lensch, MD

Jose Maria Prieto, MD

Sven G. Meuth, MD, $\mathrm{PhD}$

Xavier Nuñez, PhD

Clara Campás, PhD

Marco Pugliese, PhD

For the NeuroAdvan study

Correspondence to

Dr. Villoslada:

pvilloslada@clinic.ub.es

Supplemental data at Neurology.org/nn

\title{
Effects of diazoxide in multiple sclerosis
}

\section{A randomized, double-blind phase 2 clinical trial}

\section{OPEN}

\section{ABSTRACT}

Objective: The aim of this study was to test the safety of diazoxide and to search for signs of efficacy in patients with relapsing-remitting multiple sclerosis (RRMS).

Methods: In this multicenter, randomized, placebo-controlled, double-blind trial (treatment allocation was concealed), 102 patients with RRMS were randomized to receive a daily oral dose of diazoxide (0.3 and $4 \mathrm{mg} / \mathrm{d}$ ) or placebo for 24 weeks (NCT01428726). The primary endpoint was the cumulative number of new T1 gadolinium-enhancing lesions per patient, recorded every 4 weeks from week 4 to week 24 . Secondary endpoints included brain MRI variables such as the number of new/enlarging T2 lesions and the percentage brain volume change (PBVC); clinical variables such as the percentage of relapse-free patients, relapse rate, and change in the Expanded Disability Status Scale score; and safety and tolerability.

Results: Diazoxide was well-tolerated and it produced no serious adverse events other than 1 case of Hashimoto disease. At the 2 doses tested, diazoxide did not improve the primary endpoint or the MRI and clinical variables related to the presence of new lesions or relapses. Patients treated with diazoxide showed reduced PBVC compared with the placebo group, although such changes could be confounded by the higher disease activity of the treated group and the vascular effects of diazoxide.

Conclusion: At the doses tested, oral diazoxide did not decrease the appearance of new lesions evident by MRI. The effects in slowing the progression of brain atrophy require further validation.

Classification of evidence: This study provides Class I evidence that for patients with RRMS, diazoxide (0.3 and $4 \mathrm{mg} / \mathrm{d}$ ) does not significantly change the number of new MRI T1 gadolinium-enhancing lesions. Neurol Neuroimmunol Neuroinflamm 2015;2:e147; doi: 10.1212/NXI.0000000000000147

\section{GLOSSARY}

$\mathbf{A E}=$ adverse event; $\mathbf{B B B}=$ blood-brain barrier; $\mathbf{C U A L}=$ cumulative unique active lesion; $\mathbf{E A E}=$ experimental autoimmune encephalomyelitis; EDSS $=$ Expanded Disability Status Scale; Gad + = gadolinium-enhancing; ITT = intention-to-treat; KATP = ATP-sensitive $\mathrm{K}^{+}$; $\mathbf{M S}=$ multiple sclerosis; PBVC $=$ percentage brain volume change; PP = per-protocol; RRMS = relapsing-remitting MS; SF-36 = Short Form 36 Health Survey.

Diazoxide activates ATP-sensitive $\mathrm{K}^{+}$(KATP) channels in the smooth musculature of blood vessels and in pancreatic $\beta$-cells, increasing the concentration of glucose in the plasma and producing a fall in blood pressure through a vasodilator effect on the arterioles and a reduction in peripheral resistance. ${ }^{1}$ Accordingly, diazoxide has been approved for the treatment of malignant hypertension and hypoglycemia in Europe and the United States. In addition, diazoxide displays high affinity for KATP channels in the inner mitochondrial membrane, and most of its

From the Institut d' Investigacions Biomèdiques August Pi i Sunyer (IDIBAPS)—Hospital Clinic (P.V., A.S.), Barcelona, Spain; Unitat de RM (Servei de Radiologia) (A.R., X.M.), Departamento de Neurología-Neuroinmunología, Centro de Esclerosis Múltiple de Cataluña (Cemcat), Hospital Vall d'Hebron, Barcelona, Spain; Hospital Clinico San Carlos (R.A., C.O.-G.), Madrid, Spain; NeuroCure Clinical Research Center and Department of Neurology (F.P.), Charité University Medicine Berlin, Berlin, Germany; Hospital de La Princesa (V.M.-L.), Madrid, Spain; Hospital Germans Trias i Pujol (C.R.), Badalona, Spain; Hospital Regional Universitario (IBIMA) (O.F.), Malaga, Spain; Hospital Puerta de Hierro (A.G.-M.), Madrid, Spain; Hospital Universitari Dr Josep Trueta (L.R.-T.), IDIBGI, Girona, Spain; Hospital La Fe (B.C.), Valencia, Spain; Hospital Xeral-Cies (D.M.), Vigo, Spain; Hospital del Mar (J.E.M.-R.), Barcelona, Spain; Deutsche Klinik für Diagnostik (E.L.), Wiesbaden, Germany; Hospital Universitario Santiago de Compostela (J.M.P.), Spain; Department of Neurology (S.G.M.), University of Munster, Germany; TrialFormSupport (X.N.), Barcelona, Spain; Advancell, Advanced In Vitro Cell Technologies, S.A (C.C.), Barcelona, Spain; and Neurotec Pharma S.L (M.P.), Barcelona, Spain.

NeuroAdvan coinvestigators are listed at Neurology.org/nn.

Funding information and disclosures are provided at the end of the article. Go to Neurology.org/nn for full disclosure forms. The Article Processing Charge was paid by the authors.

This is an open access article distributed under the terms of the Creative Commons Attribution-NonCommercial-NoDerivatives License 4.0 (CC BY-NC-ND), which permits downloading and sharing the work provided it is properly cited. The work cannot be changed in any way or used commercially. 
cytoprotective and neuroprotective properties have been associated with mitochondrialtargeted preconditioning. ${ }^{2,3}$

It was recently noted that low doses of diazoxide ameliorate the clinical signs of experimental autoimmune encephalomyelitis (EAE). Diazoxide inhibits microglial activation, preventing neuronal and axonal damage, and induces the expression, activation, and nuclear translocation of nuclear factor (erythroid-derived 2)-related factor 2.,5 Diazoxide is an orally administered drug with a good safety profile and well-known pharmacologic properties, having been on the market for many years. Thus, diazoxide could represent a new treatment option for multiple sclerosis (MS).

Given that microglia play a key role in the functioning and opening of the blood-brain barrier $(\mathrm{BBB}),{ }^{6}$ and considering the modulation of microglia activation by diazoxide, we hypothesized that this drug may also modulate the opening of the BBB. If this were the case, it would be feasible to measure its efficacy by monitoring the presence of gadolinium-enhancing $(\mathrm{Gad}+)$ lesions, an endpoint extensively validated in previous clinical trials.

METHODS Patients. Men and women aged 18-55 years with relapsing-remitting MS (RRMS, McDonald criteria 20107) and an Expanded Disability Status Scale (EDSS) score of 0-5.0 were eligible for this study. The inclusion criteria required at least 1 relapse in the previous 2 years or the presence of at least $1 \mathrm{Gad}+$ lesion in the previous 1 year. The exclusion criteria were (1) patients who are candidates for treatment with drugs modifying the course of the disease according to the criteria of the regulatory agencies in each country, unless the patient refused to initiate such therapy or decided to postpone the start of this therapy; (2) patients who experienced a relapse in the 30-day period prior to the baseline visit; (3) patients on treatment with diazoxide; (4) patients with a medical condition such as hypotension, insulinoma, hyperuricemia, or diabetes defined by American Diabetes Association criteria; (5) patients with other conditions, including drug abuse, liver transplantation, inability to provide informed consent, or inability to perform all the procedures in the clinical trial; (6) patients with contraindications for MRI studies; (7) patients with contraindications for treatment with diazoxide, excipients, or gadolinium-based agents; (8) patients on corticosteroid therapy in the last month; (9) patients on interferon $\beta$ or glatiramer acetate therapy in the past 3 months; (10) patients on natalizumab or fingolimod therapy in the past 6 months; (11) patients treated with chemotherapy (mitoxantrone, azathioprine, cyclophosphamide, cladribine, methotrexate) or who entered previous trials of treatments under development; and (12) patients with a positive pregnancy test, those currently breast-feeding, or women of childbearing potential not using highly effective methods of contraception.

Standard protocol approvals, registrations, and patient consents. The trial was approved by the local institutional review board at each center and by the Spanish and German medical agencies. Patients were included after providing their informed consent.

Study design. This was a double-blind, placebo-controlled, multicenter phase 2a study to determine the safety of diazoxide and to search for evidence of efficacy of 2 doses of diazoxide in patients with RRMS (ClinicalTrials.gov: NCT01428726; EUDRA-CT: 2010-023048-34). The trial was conducted at 16 sites (13 in Spain and 3 in Germany) in accordance with the Helsinki Declaration ${ }^{8}$ and adhering to the International Conference on Harmonization Guidelines for Good Clinical Practice.' All investigators and patients were blinded to the treatment and to the blood glucose and diazoxide levels, unless they were alerted for safety reasons. Diazoxide and placebo were prepared as identical tablets with no differences in taste or appearance.

One hundred two patients were randomly assigned to 3 groups: diazoxide $0.3 \mathrm{mg} / \mathrm{d}$, diazoxide $4 \mathrm{mg} / \mathrm{d}$, or placebo (ratio 1:1:1) administered orally once daily. Block randomization was performed using 2 blocks of 6 elements with random sequences of the 3 arms in each center using a randomization seed in order to ensure its reproducibility and using SPSS v17 software and macro Generation of Random Sequences (!RNDSEQ).

Doses were selected on the basis of preclinical studies in an animal model of $\mathrm{MS}^{4,5}$ in order to maintain the doses below those at which diazoxide induces hyperglycemia or hypotension (100 $\mathrm{mg} / \mathrm{kg} / \mathrm{d}$ ). Patients received diazoxide in 1 daily oral dose of $0.3 \mathrm{mg}$ or $4 \mathrm{mg}$ (total dose) from day 1 to the end of week 24 . Study visits took place at screening, at baseline, on day 1 (randomization), and every 4 weeks until the end of the 24-week treatment period or drug discontinuation. Treatment allocation was concealed without breaking the blinding until the end of the study. At the end of the follow-up, the patients could enroll in an additional 24-week observation period.

Confirmed relapse was defined as the occurrence of new symptoms or a worsening of previously stable or improving symptoms and signs lasting more than 24 hours, not associated with fever, and accompanied by an increase of at least half a point on the EDSS. When warranted, relapses were managed by the treating physician according to a standardized scheme: IV administration of up to $1,000 \mathrm{mg}$ of methylprednisolone per day for 3-5 days. For the duration of the methylprednisolone therapy, glycemia was monitored daily using a glucose finger prick test. Diazoxide treatment was maintained during the relapses and the study schedule was not changed (the visit and MRI schedule remained unaltered) unless patients needed to use prohibited concomitant treatments. EDSS was assessed by an independent neurologist not involved in patient care at screening, at baseline, every 4 weeks, and at unscheduled visits in the case of MS relapse.

MRI. MRI scans were performed at baseline and every 4 weeks until the end of the study (week 24). Patients enrolled in the follow-up study were subjected to an additional scan at week 48. Patients received a double dose of the contrast agent $(0.2 \mathrm{mmol} / \mathrm{kg})$, and the same agent was used for all patients at the same center, with a latency of 10 minutes. New and enhancing lesions were identified by certified radiologists, and $\mathrm{T} 1$ and $\mathrm{T} 2$ lesion volumes were determined by trained technicians using the Jim software (Xinapse Limited Systems, Aldwincle, UK). The normalized brain volume at baseline and the percentage brain volume change (PBVC) between baseline and month 24 were calculated using the Structural Image Evaluation using Normalization of Atrophy program. ${ }^{10}$ Black holes were defined as areas of unequivocal low signal intensity compared with normal-appearing white matter that did not show contrast uptake and were concordant with a hyperintense lesion seen on T2-weighted imaging. Finally, exploratory tissue-type segmentation was used to calculate separate 
estimates of gray matter, white matter, and CSF volumes with Statistical Parametric Mapping (SPM5). MRI analysis was performed at the MRI unit of the "Centro de Esclerosis Múltiple de Cataluña” (Cemcat), Hospital Vall d'Hebron, Barcelona, Spain.

Study endpoints. The primary efficacy endpoint was the cumulative number of new Gad+ lesions on T1-weighted sequences from week 4-24. We selected this endpoint based on the effects of diazoxide on microglia activation and closing of the $\mathrm{BBB}$ and because this endpoint has been validated in many previous shortduration trials (6 months). Secondary MRI endpoints were cumulative number of new/enlarged lesions on T2-weighted sequences for all MRIs; cumulative number of new/increased lesions on T2-weighted sequences in the 6 months after starting therapy (compared with the baseline MRI); cumulative number of combined unique active lesions (CUALs), addition of new or enlarged lesions on T2-weighted sequences that do not enhance with gadolinium and new Gad+ lesions for all MRIs; cumulative number of CUALs, addition of new or enlarged lesions on T2-weighted sequences that do not enhance with gadolinium and new Gad+ lesions in the 6 months after starting therapy (compared with the baseline MRI); number of patients without Gad + lesions in T1-weighted sequences in the 6 months after starting therapy; and PBVC. Secondary clinical endpoints were relapse-free status, relapse rate, number of relapses requiring corticosteroid treatment, time to first relapse during the trial, change in EDSS, and quality of life assessed with the Short Form 36 Health Survey (SF-36). Secondary safety endpoints were incidence, nature, and severity of adverse events (AEs) during the 6 months of therapy up until 15 days after the last dose of diazoxide or placebo, including control of glucose levels, glycated hemoglobin, blood pressure, and presence of hirsutism.

Statistical analysis. The primary alternate hypothesis was that the cumulative number of new T1 Gad+ lesions observed in all MRIs would be distinct in patients treated with diazoxide

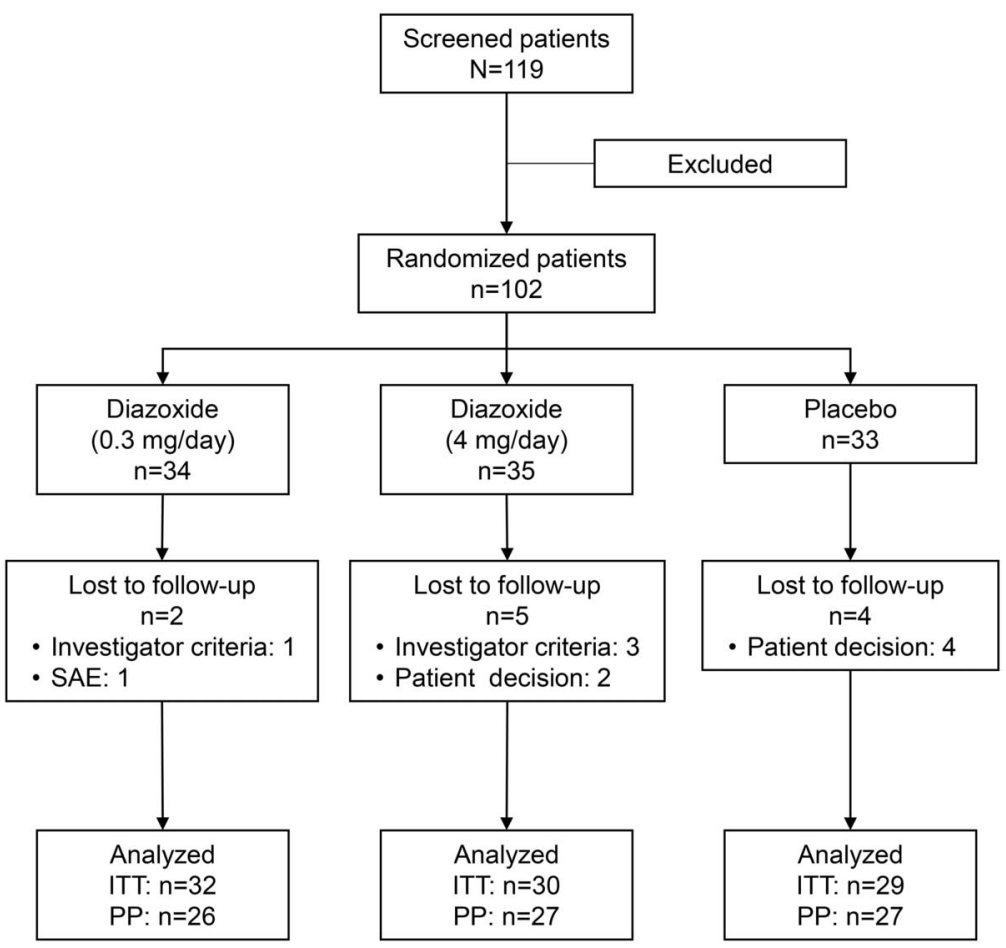

$\mathrm{ITT}=$ intention-to-treat; $\mathrm{PP}=$ per-protocol; $\mathrm{SAE}=$ serious adverse event.
( 0.3 or $4 \mathrm{mg} / \mathrm{d}$ ) and those who received placebo. The null hypothesis was tested in a negative binomial regression model, as we considered this to best explain the distribution of new Gad+ lesions. ${ }^{11}$ The analysis was planned for an intention-to-treat (ITT) population (any patient who was randomized, received treatment, and had at least 1 postbaseline efficacy variable completed) and a per-protocol (PP) population (any patient who was randomized and received the protocol-required treatment and processing). In the PP population, no data input methods were used. In the ITT population, when primary outcome observations were missing in the study visits, the patient was assigned the median of the number of new lesions for the remaining visits.

The univariate analysis of categorical variables involved the $\chi^{2}$ or Fisher exact test, and continuous variables were assessed with a $t$ test, a Mann-Whitney test, or a Wilcoxon test, as appropriate. Differences in the number of new T2 lesions and CUALs were analyzed using the negative binomial distribution, as described previously. ${ }^{11}$ Paired samples with continuous variables were analyzed using a $t$ test or Wilcoxon signed-rank test. The time-to-event analysis was achieved with a Cox analysis. Multivariate analysis was performed with linear generalized models or generalized estimating equations with the evolution between visits as an outcome measure. $p$ Values $\leq 0.05$ were considered significant in all tests, which were carried out with the SAS statistical package v9.2.

The underlying assumption for calculating the sample size was a minimum effect between groups of 2 lesions and a common SD of $2.55 .{ }^{12}$ We assumed a power of $80 \%$ and an $\alpha$ error of 0.025 . Sample size estimation was based on the $t$ test. We took into account that endpoint assessment would be performed after a 6-month follow-up, so we estimated a loss rate of $10 \%$. Finally, the study sample size was calculated with GRANMO 7.10 software, which indicated that 35 patients were needed in each group (a total of 105 patients) to detect a treatment effect $\geq 2$ lesions with a common SD of 2.55 and a loss rate of $10 \%$.

Primary research questions and classification of evidence. The aim of this study was to test the safety of diazoxide and to search for signs of efficacy in patients with RRMS. This study provides Class I evidence that diazoxide is safe and well-tolerated in patients with MS. It does not decrease the presence of new lesions on MRI and it slows the progression of brain atrophy.

RESULTS Description of the cohort. Of the 119 patients screened between June 2011 and March 2013, 102 were randomized to receive diazoxide $(0.3$ or 4 $\mathrm{mg}$ ) or the placebo orally once daily (the patient distribution is shown in the figure). In the 2 groups that received diazoxide, $5.9 \%(0.3 \mathrm{mg})$ and $13.9 \%(4 \mathrm{mg})$ of patients prematurely discontinued the treatment, compared with $12.1 \%$ of the patients who received placebo. Doubleblinding was maintained until the end of the study. The demographic and baseline disease characteristics were generally similar in each treatment group (table 1).

Efficacy for the MRI and clinical outcomes. In the diazoxide groups, we found no differences in the primary endpoint in the ITT or PP analysis (mean cumulative number of new T1 Gad+ lesions at week 24) or in the other MRI variables associated with the presence of new lesions (cumulative number of new/enlarged lesions in T2-weighted sequences for all MRIs, cumulative number of new/increased lesions on T2-weighted sequences in the 6 months after starting therapy 
Table 1 Demographics of the cohort at baseline (ITT population)

\begin{tabular}{|c|c|c|c|c|}
\hline & Diazoxide $0.3 \mathrm{mg} / \mathrm{d}$ & Diazoxide $4 \mathrm{mg} / \mathrm{d}$ & Placebo & $p$ Value \\
\hline $\mathrm{n}$ & 34 & 35 & 33 & \\
\hline Age, $y$, mean $\pm S D$ & $41.3 \pm 6.9$ & $41.0 \pm 7.4$ & $42.4 \pm 7.6$ & NS \\
\hline Sex, M/F & $9 / 25$ & $15 / 20$ & $7 / 26$ & $<0.05$ \\
\hline $\begin{array}{l}\text { No. previous relapses within past } 2 y \text {, } \\
\text { mean } \pm \text { SD }\end{array}$ & $1.3 \pm 0.52$ & $1.5 \pm 1.28$ & $1.3 \pm 0.48$ & NS \\
\hline EDSS score, median (range) & $1.5(0-5.0)$ & $1.5(0-5.0)$ & $2.0(0-4.0)$ & NS \\
\hline Previous DMD, Y/N & $12 / 22$ & $13 / 22$ & $9 / 24$ & $<0.05$ \\
\hline No. T2 lesions & $58.4 \pm 37.04(45.3-71.6)$ & $68.8 \pm 62.16(47.4-90.2)$ & $55.9 \pm 44.11(40.2-71.5)$ & NS \\
\hline Volume T2 lesions, $\mathrm{cm}^{3}$ & $\begin{array}{l}6,856.6 \pm 11,199 \\
(2,885.5-10,828)\end{array}$ & $\begin{array}{l}6,278.7 \pm 6,663.4 \\
(3,989.8-8,567.7)\end{array}$ & $\begin{array}{l}5,461.5 \pm 6,694.6 \\
(3,087.7-7,835.3)\end{array}$ & $<0.05$ \\
\hline No. Gad+ lesions & $1.5 \pm 2.33(0.7-2.3)$ & $1.4 \pm 2.25(0.6-2.1)$ & $1.1 \pm 1.88(0.4-1.8)$ & NS \\
\hline NBV & $\begin{array}{l}1,047,831 \pm 52,645 \\
(1,028,850-1,066,811)\end{array}$ & $\begin{array}{l}1,034,549 \pm 59,387 \\
(1,013,138-1,055,960)\end{array}$ & $\begin{array}{l}1,043,200 \pm 56,874 \\
(1,021,566-1,064,834)\end{array}$ & NS \\
\hline Volume black holes, $\mathrm{cm}^{3}$ & $\begin{array}{l}564.45 \pm 716.106 \\
(268.86-860.05)\end{array}$ & $\begin{array}{l}832.82 \pm 1,309.819 \\
(279.73-1,385.91)\end{array}$ & $\begin{array}{l}1,066.14 \pm 1,578.976 \\
(366.06-1,766.22)\end{array}$ & $<0.05$ \\
\hline \multicolumn{5}{|l|}{ No. black holes, n (\%) } \\
\hline 0 & $5(14.71)$ & $7(20.00)$ & $8(24.24)$ & NS \\
\hline $1-5$ & $14(41.10)$ & $14(40.01)$ & 13 (39.39) & NS \\
\hline $6-10$ & $8(23.53)$ & $6(17.14)$ & 4 (12.12) & $<0.05$ \\
\hline $11-20$ & 3 (8.82) & $3(8.57)$ & 3 (9.09) & NS \\
\hline$>20$ & 1 (2.94) & $1(2.86)$ & $2(6.06)$ & NS \\
\hline
\end{tabular}

Abbreviations: DMD = disease-modifying drugs; EDSS = Expanded Disability Status Scale; Gad + = gadolinium-enhancing; ITT = intention-to-treat; NBV = normalized brain volume; NS = not significant.

Unless otherwise indicated, data are expressed as mean \pm SD (range).

compared with the baseline MRI, cumulative number of CUALs, and number of patients without lesions in $\mathrm{Gad}+\mathrm{T} 1$-weighted sequences in the 6 months after starting therapy; table 2). We found a decrease in the PBVC in the patients who received diazoxide compared with placebo $(0.3 \mathrm{mg}$ arm: -0.1 [SD 0.76 ], $p=$ 0.0104; $4 \mathrm{mg}$ arm: 0.02 [SD 0.60], $p=0.0124$; placebo arm: -0.39 [SD 0.54]). The number of new T2/Proton Density lesions converting to black holes was not different between arms (diazoxide $4 \mathrm{mg}$ arm: 0.06\% [SD 0.22]; diazoxide $0.3 \mathrm{mg}$ arm: $0.11 \%$ [SD 0.18]; placebo arm: $0.17 \%$ [SD 0.50]; Kruskal-Wallis test, $p=0.32$ ). As expected in light of the small sample size of this trial, we found no differences in the clinical variables of relapse-free status, relapse rate, number of relapses requiring corticosteroid treatment, time to first relapse during the trial, change in EDSS, or quality of life (SF-36) (table 2).

Safety and tolerability. There were 6 serious AEs during the study, 3 of which were considered to be severe: biliary colic, pregnancy (severe), fracture of the left radius, duodenal ulcer (severe), acute autoimmune hypothyroidism, reduced libido (severe), and fracture of the left clavicle (table 3). All AEs occurred in patients receiving diazoxide, except for the patient who reported reduced libido, who received placebo.
Only autoimmune hypothyroidism was considered to be related to the therapy, and therapy was discontinued only in the case of concurrent pregnancy. Regarding the AEs specifically related to the known clinical effects of diazoxide, such as hyperglycemia or hypotension, glucose levels always remained within the limits of normality, confirming that the doses of the drug used were lower than those that induce hyperglycemic and hypotensive effects.

DISCUSSION In this study we evaluated the effects of oral diazoxide in preventing disease activity and tissue damage in RRMS as assessed by MRI. Diazoxide is a potassium channel opener, and preclinical research shows that at very low doses it can modulate microglia activation and produce protective effects in animal models of MS. ${ }^{4,5}$ Although the action of diazoxide on microglia would be sufficient to explain the improvements observed in EAE mice after diazoxide treatment, the presence of functional KATP channels in other glial cells and neurons could explain any additional benefits in the CNS produced by the drug. ${ }^{13-17}$ These studies also suggest that diazoxide could produce neuroprotection through different mechanisms depending on the drug concentration and due to its selective activation of mitoKATP channels. ${ }^{5,18-20}$ Multiple mechanisms could contribute to demyelination and neuroaxonal injury in 
MS. ${ }^{21,22}$ It has been postulated that chronic microglial activation is partially responsible for the damage to the CNS during attacks, as well as between attacks, contributing to disease progression. ${ }^{23,24}$ For this reason, downmodulating chronic microglia activation may prevent CNS damage during acute MS relapses, as well as in the progressive phases. Also, it has been shown that mito-KATP activation by diazoxide prevents neuronal oxidative stress and excitotoxic cell death, whereas at the mitochondrial level it can activate defense and antiapoptotic mechanisms. ${ }^{2,25}$

Considering diazoxide has been on the market for decades and has an excellent safety profile, we evaluated the efficacy of low doses of diazoxide in RRMS. The objective of the trial was to obtain preliminary evidence of efficacy using the cumulative number of new $\mathrm{T} 1 \mathrm{Gad}+$ lesions as a surrogate endpoint. This endpoint was selected because it is a sensitive endpoint in clinical trials with immunomodulatory drugs for RRMS with strong validation in many previous trials. The evidence that the modulation of microglia affects the integrity of the $\mathrm{BBB}$ and the development of parenchymal lesions ${ }^{6}$ suggested that this endpoint might be sensitive to the effects of diazoxide. In addition, the trial included secondary endpoints that are more specifically related to neuroprotection and microglial modulation, such as the prevention of brain volume loss (brain atrophy) or the development of black holes. Regarding the primary endpoint, we found no differences between groups with a negative binomial distribution, ${ }^{11}$ and the treated group had higher activity. Even if patients were randomly distributed, the group receiving diazoxide started the trial with higher disease activity in terms of the number of Gad+ lesions than the placebo group. This higher activity in the treated group was maintained throughout the trial. Therefore, our interpretation is that the treated group was a more active group than the placebo group, which explains the differences between groups in increasing the number of contrast-enhancing lesions better than a true effect of the drug. Thus, we conclude that at the dose tested, diazoxide does not seem to have a significant effect that impedes the appearance of new Gad+ lesions.

Regarding the effects on brain atrophy, we found that the PBVC progressed more slowly in patients who received diazoxide and in those on the higher dose. These findings are consistent with a recent study reporting the validity of brain atrophy measurement as an outcome measure for phase 2 trials in RRMS. ${ }^{26}$ However, the atrophy effects observed may also be secondary to fluid shifts and not true protection against brain injury, considering the fact that the treated group had more active disease and the vasodilator effects and the effects on peripheral resistance displayed by diazoxide.

This study indicates that diazoxide is a safe drug that is well-tolerated in patients with MS, but we 


\section{Table $3 \quad$ Adverse events}

Diazoxide $0.3 \mathrm{mg} / \mathrm{d}$ Diazoxide $4 \mathrm{mg} / \mathrm{d}$ Placebo

$\begin{array}{llll}\text { Any AEs } & 26(76.47) & 27(77.14) & 25(78.13) \\ \text { Any study intervention-related AE } & 6(17.65) & 6(17.14) & 7(21.87) \\ \text { AEs leading to treatment withdrawal } & 1(2.94) & 1(2.86) & 0(0) \\ \text { Any SAEs } & 4(11.76) & 2(5.71) & 0(0) \\ \text { Any study intervention-related SAE } & 0(0) & 1(2.86) & 0(0)\end{array}$

Abbreviations: $\mathrm{AE}=$ adverse event; $\mathrm{SAE}=$ serious adverse event. Data are $\mathrm{n}(\%)$.
Idec, and Olea; is on the editorial board for American Journal of Neuroradiology and Neuroradiology; and is on the speakers' bureau for Bayer, Teva Pharmaceutical Industries Ltd, Genzyme, Bracco, Merck-Serono, Biogen, and Olea. X. Montalban is on the scientific advisory board for and received travel funding from Novartis, Teva Pharmaceuticals, Merck, Biogen, Bayer, Almirall, Actelion, Genzyme, Octapharma, Receptos, Roche, Sanofi, and Trophos; is on the editorial board for Multiple Sclerosis, Journal of Neurology, The International MS Journal, Revista Neurologia, and Therapeutic Advances in Neurological Disorders; has consulted for Novartis, Teva Pharmaceuticals, Merck, Biogen, Bayer, Almirall, Actelion, Genzyme, Octapharma, Receptos, Roche, Sanofi, and Tropho; and received research support from Multiple Sclerosis Foundation of Barcelona. R. Arroyo is on the scientific advisory board for and received speaker honoraria from Teva, Biogen, Novartis, Merck-Serono, Roche, Bayer, Genzyme, Sanofi, and Almirall. F. Paul is on the scientific advisory board for Novartis and MedImmune; received speaker honoraria and travel grants from Bayer, Novartis, Biogen Idec, Teva, Sanofi-Aventis/Genzyme, and Merck-Serono; is an academic editor for PLoS ONE; is an associate editor for Neurology: Neuroimmunology \& Neuroinflammation; has consulted for Sanofi, Genzyme, Biogen, and MedImmune; and received research support from Bayer, Novartis, Biogen Idec, Teva, SanofiAventis/Genzyme, Merck-Serono, German Research Council, Werth Stiftung of the City of Cologne, German Ministry of Education and Research, Arthur Arnstein Foundation Berlin, Guthy Jackson Charitable Foundation, and National Multiple Sclerosis Society (US). V. Meca-Lallana is on the scientific advisory board for Roche and received travel funding from Biogen Idec, Novartis, Merck, and Teva. C. Ramo received travel funding from Biogen and Novartis and received research support from Biogen, Genzyme, Novartis, Almirall, Instituto de Salud Carlos III, and Spain Fondo de Investigaciones Sanitarias. O. Fernandez has received honoraria as a consultant in advisory boards and as chairmen or lecturer in meetings and has participated or participates at present in clinical trials and other research projects promoted by Biogen Idec, Bayer-Schering, Merck-Serono, Teva, Novartis, Actelion, Almirall, and Allergan and is on the editorial board for Revista de Multiple Sclerosis. A. Saiz is on the scientific advisory board for Biogen Idec and Merck-Serono and received travel funding and/or speaker honoraria from and has consulted for Bayer-Schering, Merck-Serono, Biogen Idec, Sanofi-Aventis, Teva Pharmaceuticals, and Novartis. A. Garcia-Merino is on the scientific advisory board for Biogen Idec, Novartis, Roche, Genzyme, and Merck; received travel funding and/or speaker honoraria from Biogen Idec, Novartis, Almirall, Genzyme, Roche, and Merck; and received research support from Novartis, Biogen Idec, and FIS. L. Ramió-Torrentà is on the scientific advisory board for Biogen, Roche, Novartis, and Teva and received gifts from Biogen, Roche, Novartis, Teva, Bayer-Schering, Merck-Serono, and Genzyme. B. Casanova is on the scientific advisory board for Biogen Idec, Genzyme, Teva, and Novartis. C. Oreja-Guevara is on the scientific advisory board for Genzyme and received speaker honoraria from Biogen, Novartis, Teva, and Genzyme. D. Muńoz reports no disclosures. J.E. Martinez-Rodriguez has consulted for Roche and Bayer. E. Lensch received speaker honoraria from Bayer GmbH and Merck-Serono GmbH. J.M. Prieto is on the scientific advisory board for and received travel funding and/or speaker honoraria from Biogen, Novartis, Bayer, Merck-Serono, Teva, Genzyme, and Almirall and has consulted for Biogen, Novartis, Bayer, Merck-Serono, Teva, Genzyme, and Almirall. S.G. Meuth is on the editorial board for PLoS One and received honoraria for lecturing, travel expenses for attending meetings, and financial research support from Bayer, BayerSchering, Biogen Idec, Genzyme, Merck-Serono, MSD, Novartis, Novo Nordisk, Sanofi-Aventis, and Teva. X. Nuñez reports no disclosures. C. Campás was managing director for Advancell, Advanced In Vitro Cell Technology, SA SME biomedicine company. M. Pugliese has applied for a PCT application "Diazoxide for use in the treatment of a central nervous system (CNS) autoimmune demyelinating disease," (application number PCT/EP2011/050049). He is the CEO at Neurotec Pharma and also holds shares in the company. Go to Neurology.org/nn for full disclosure forms.

Received March 17, 2015. Accepted in final form July 15, 2015.

\section{REFERENCES}

1. Mannhold R. KATP channel openers: structure-activity relationships and therapeutic potential. Med Res Rev 2004;24:213-266. 
2. Busija DW, Gaspar T, Domoki F, Katakam PV, Bari F Mitochondrial-mediated suppression of ROS production upon exposure of neurons to lethal stress: mitochondrial targeted preconditioning. Adv Drug Deliv Rev 2008;60: 1471-1477.

3. Correia SC, Santos RX, Perry G, Zhu X, Moreira PI, Smith MA. Mitochondria: the missing link between preconditioning and neuroprotection. J Alzheimers Dis 2010; 20(suppl 2):S475-S485.

4. Virgili N, Espinosa-Parrilla JF, Mancera $P$, et al. Oral administration of the KATP channel opener diazoxide ameliorates disease progression in a murine model of multiple sclerosis. J Neuroinflammation 2011;8:149.

5. Virgili N, Mancera P, Wappenhans B, et al. K(ATP) channel opener diazoxide prevents neurodegeneration: a new mechanism of action via antioxidative pathway activation. PLoS One 2013;8:e75189.

6. Ransohoff RM, Perry VH. Microglial physiology: unique stimuli, specialized responses. Annu Rev Immunol 2009; 27:119-145.

7. Polman $\mathrm{CH}$, Reingold SC, Banwell B, et al. Diagnostic criteria for multiple sclerosis: 2010 revisions to the McDonald criteria. Ann Neurol 2011;69:292-302.

8. WMA. World Medical Association Declaration of HelsinkiEthical Principles for Medical Research Involving Human Subjects. Ferney-Voltaire, France: World Medical Association; 2008.

9. ICH. Guideline for Good Clinical Practice. 1996. Available at: http://www.ich.org/products/guidelines/efficacy/article/efficacyguidelines.html. Accessed May 10, 2011.

10. Smith SM, Zhang Y, Jenkinson M, et al. Accurate, robust, and automated longitudinal and cross-sectional brain change analysis. Neuroimage 2002;17:479-489.

11. Velez de Mendizabal N, Hutmacher MM, Troconiz IF, et al. Predicting relapsing-remitting dynamics in multiple sclerosis using discrete distribution models: a population approach. PLoS One 2013;8:e73361.

12. Sormani MP, Miller DH, Comi G, et al. Clinical trials of multiple sclerosis monitored with enhanced MRI: new sample size calculations based on large data sets. J Neurol Neurosurg Psychiatry 2001;70:494-499.

13. Sun XL, Zeng XN, Zhou F, Dai CP, Ding JH, Hu G. KATP channel openers facilitate glutamate uptake by GluTs in rat primary cultured astrocytes. Neuropsychopharmacology 2008;33:1336-1342.
14. Zhang S, Liang R, Zhou F, Huang X, Ding JH, Hu G. Reversal of rotenone-induced dysfunction of astrocytic connexin 43 by opening mitochondrial ATP-sensitive potassium channels. Cell Mol Neurobiol 2011;31:111-117.

15. Fogal B, McClaskey C, Yan S, Yan H, Rivkees SA. Diazoxide promotes oligodendrocyte precursor cell proliferation and myelination. PLoS One 2010;5:e10906.

16. Roseborough G, Gao D, Chen L, et al. The mitochondrial K-ATP channel opener, diazoxide, prevents ischemiareperfusion injury in the rabbit spinal cord. Am J Pathol 2006;168:1443-1451.

17. Wang L, Zhu QL, Wang GZ, et al. The protective roles of mitochondrial ATP-sensitive potassium channels during hypoxia-ischemia-reperfusion in brain. Neurosci Lett 2011;491:63-67.

18. Nakagawa I, Wajima D, Tamura K, Nishimura F, Park YS, Nakase H. The neuroprotective effect of diazoxide is mediated by mitochondrial ATP-dependent potassium channels in a rat model of acute subdural hematoma. J Clin Neurosci 2013;20:144-147.

19. Abe E, Fujiki M, Nagai Y, et al. The phosphatidylinositol3 kinase/Akt pathway mediates geranylgeranylacetoneinduced neuroprotection against cerebral infarction in rats. Brain Res 2010;1330:151-157.

20. Yamauchi T, Kashii S, Yasuyoshi H, Zhang S, Honda Y, Akaike A. Mitochondrial ATP-sensitive potassium channel: a novel site for neuroprotection. Invest Ophthalmol Vis Sci 2003;44:2750-2756.

21. Franklin RJ, ffrench-Constant C, Edgar JM, Smith KJ. Neuroprotection and repair in multiple sclerosis. Nat Rev Neurol 2012;8:624-634.

22. Chaudhuri A. Multiple sclerosis is primarily a neurodegenerative disease. J Neural Transm 2013;120:1463-1466.

23. Benarroch EE. Microglia: multiple roles in surveillance, circuit shaping, and response to injury. Neurology 2013; 81:1079-1088.

24. Lassmann H, van Horssen J, Mahad D. Progressive multiple sclerosis: pathology and pathogenesis. Nat Rev Neurol 2012;8:647-656.

25. Fornazari M, de Paula JG, Castilho RF, Kowaltowski AJ. Redox properties of the adenoside triphosphate-sensitive $\mathrm{K}+$ channel in brain mitochondria. J Neurosci Res 2008; $86: 1548-1556$.

26. van den Elskamp IJ, Boden B, Dattola V, et al. Cerebral atrophy as outcome measure in short-term phase 2 clinical trials in multiple sclerosis. Neuroradiology 2010;52:875-881. 


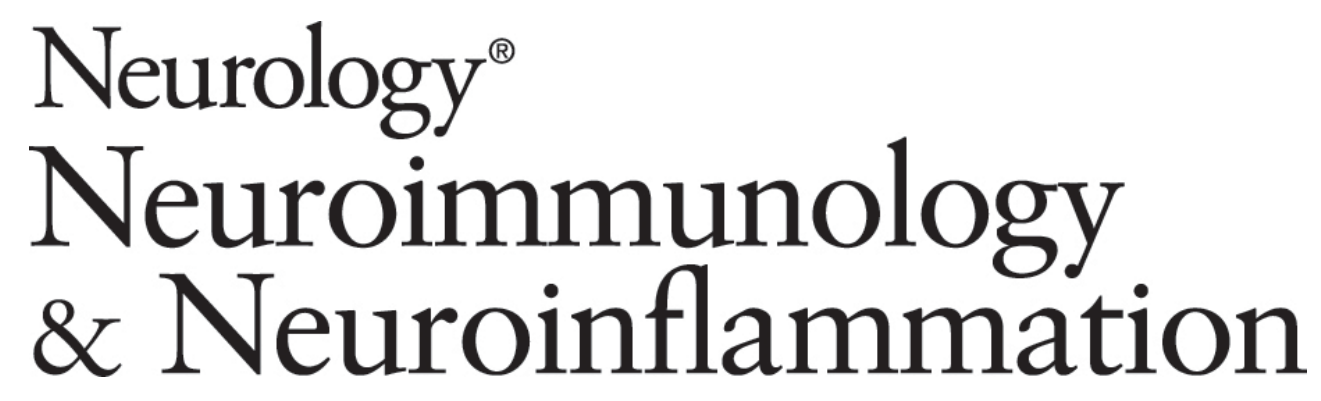

Effects of diazoxide in multiple sclerosis: A randomized, double-blind phase 2 clinical trial

Pablo Villoslada, Alex Rovira, Xavier Montalban, et al.

Neurol Neuroimmunol Neuroinflamm 2015;2;

DOI 10.1212/NXI.0000000000000147

This information is current as of September 10, 2015

Neurol Neuroimmunol Neuroinflamm is an official journal of the American Academy of Neurology.

Published since April 2014, it is an open-access, online-only, continuous publication journal. Copyright $($ ) 2015 American Academy of Neurology. All rights reserved. Online ISSN: 2332-7812.

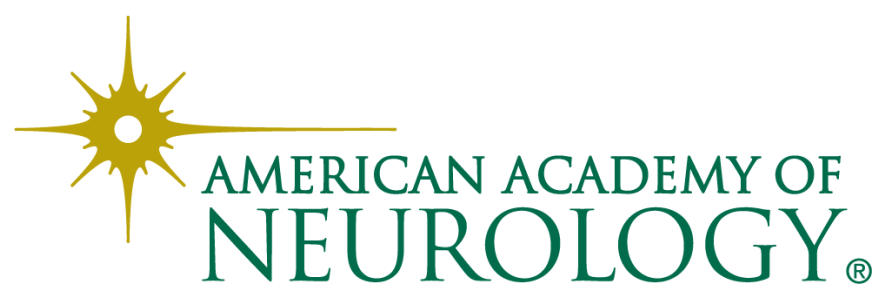




\section{Updated Information \&} Services

\section{Supplementary Material}

References

Subspecialty Collections

Permissions \& Licensing

Reprints including high resolution figures, can be found at:

http://nn.neurology.org/content/2/5/e147.full.html

Supplementary material can be found at:

http://nn.neurology.org/content/suppl/2015/09/10/2.5.e147.DC1

This article cites 24 articles, 2 of which you can access for free at: http://nn.neurology.org/content/2/5/e147.full.html\#\#ref-list-1

This article, along with others on similar topics, appears in the following collection(s):

\section{Class I}

http://nn.neurology.org//cgi/collection/class_1

Clinical trials Randomized controlled (CŌNSORT agreement)

$\mathrm{http} / / / \mathrm{nn}$. neurology.org//cgi/collection/clinical_trials_randomized_cont rolled_consort_agreement

MRI

http://nn.neurology.org//cgi/collection/mri

Multiple sclerosis

http://nn.neurology.org//cgi/collection/multiple_sclerosis

Volumetric MRI

http://nn.neurology.org//cgi/collection/volumetric_mri

Information about reproducing this article in parts (figures,tables) or in its entirety can be found online at:

http://nn.neurology.org/misc/about.xhtml\#permissions

Information about ordering reprints can be found online: http://nn.neurology.org/misc/addir.xhtml\#reprintsus

Neurol Neuroimmunol Neuroinflamm is an official journal of the American Academy of Neurology.

Published since April 2014, it is an open-access, online-only, continuous publication journal. Copyright $\odot$ 2015 American Academy of Neurology. All rights reserved. Online ISSN: 2332-7812.

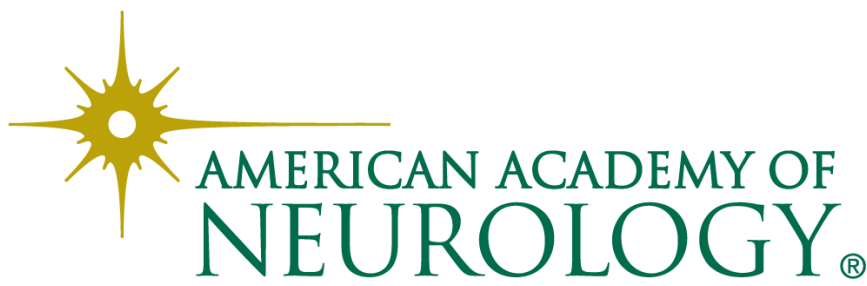

